\title{
AN ANALYTICAL STUDY OF SEARCH ENGINE OPTIMIZATION (SEO) TECHNIQUES: TO MAXIMIZE NUMBER OF TRAVELERS ON AN E-CONTENT MATERIAL WEBSITE
}

\author{
Gowtham Aashirwad Kumar \\ Assistant Professor \& Research Scholar, \\ Department of Management Studies, \\ Bharath Institute of Higher Education and Research (BIHER), India \\ Dr A Ravikumar \\ Associate Professor \& Research Supervisor, \\ Department of Management Studies, \\ Bharath Institute of Higher Education and Research (BIHER), India
}

\begin{abstract}
Web index is the most conspicuous device to extricate data from web (www).It is an enormous dispersed computerized data. The idea of data recovery frameworks is to just get the contribution from client as keywords, process it at that point contrasted and the database and the data is given to the client. search motor enhancement is the procedure which is utilized to expand the significance of the pages which are most much of the time visited which the client happen upon regularly. This article presents and talks about the idea of search motor advancement, highlights of web index and diagram of components and devices utilized in web crawler advancement. In website streamlining there are chiefly two fundamental calculations utilized page rank and Hypertext Initiated Topic Search(HITS). In page rank calculation, joins associated with different pages and sites are given more significance and weightage while in the HITS calculation question based hunt is performed.
\end{abstract}

Keywords: Degree, Product, Online, Advancement.

Cite this Article: Gowtham Aashirwad Kumar and Dr A Ravikumar, An Analytical Study of Search Engine Optimization (SEO) Techniques: To Maximize Number of Travelers on an E-Content Material Website, International Journal of Management (IJM), 11 (1), 2020, pp. 113-118.

http://iaeme.com/Home/issue/IJM?Volume $=11 \&$ Issue $=1$ 


\section{INTRODUCTION}

In the course of recent years, increasingly more Internet visitors are arriving at sites via web seek tools rather than through direct connections from every other website online page. Web crawlers have come to contain a prominent position within the online international and are being applied to get an amazing variety of information including things, occasions, individuals, and spots. the web crawler is also coming to expect a extra distinguished process as a primary connection between corporations that usage the internet to bring together their photograph and find out their meant interest. Step with the aid of step instructions to accomplish a excessive positioning in such query gadgets given certain pursuit phrases or expressions has end up a problem of tons of enthusiasm for the advanced advertising and marketing situation.

\section{REVIEW OF LITERATURE}

Sabin, Higgs, Riabov and Mereira, 2005; McCown, (2010) ${ }^{1}$

Search engine optimization has discovered its place into a few school figuring and IT guides.

McCown $(2010)^{2}$ depicts an innovative undergrad seminar on application Development, in which understudies who have programming advancement enjoy compose code to make or improve open source net search tool application. They too discern out how internet indexes and crawlers paintings to accumulate and type out online facts to give essential outcomes. Understudies find out the purpose huge since an internet index is often one's passage point to the on line.

Sandvig, $(2007)^{3}$, p. 215) Website layout enhancement has its spot out of doors of the processing observe corridor too. Understudies attempted out Ecommerce and e-business publications spread search engine marketing at a few colleges. because the Web has advanced over the previous decade, online business guides have superior from '"gentler' aptitudes, for instance, venture the board, E-business ideas, and teamwork...To contain greater server-side programming and database aptitudes" even as increasingly "specialised and on line business ideas such as e-promoting, security, SSL, internet administrations, site layout improvement, server arrangement, purchaser following, [and] propelled database ideas.

\section{OBJECTIVES OF STUDY}

\subsection{Primary Objectives}

To study about the search engine optimization (SEO) techniques: to maximize number of travelers on an e-content material website.

\subsection{Secondary Objectives}

- To fathom the system of program Optimization (SEO).

- To get a handle on the utilization of instruments of SEO and to inquire about the suitability of SEO on the area to the extent improved number of visitors.

- States that a SEO framework and to improve it.

\section{NEED FOR STUDY}

To analyse the maximum number of travellers who are using e-content in website in order develop the content to the further extent. 


\section{RESEARCH METHODOLOGY}

Research is a unique obligation to the ebb and buoy store of limit. It is the task for reality with the help of watch acknowledgment, appraisal and fundamentals. The mission for certainties by techniques for destinations and efficient strategy for finding decision to a difficulty is explore.

\subsection{Research Design}

Reasonable investigations game plan end up being utilized quickly. It gets an idea about a goliath a part of Publicizing Research. The structure is to supply a cautious photograph of exact bits of the publicizing condition.

\subsection{Sample Size}

An example size alludes to the scope of devices to be chosen from the masses to establish an example. 100 respondents were chosen as tests for review.

\subsection{Sampling Technique}

A model size insinuates the volume of devices to be browsed the majority to line up an version. a hundred respondents have been picked as checks for survey.

The Sampling method taken for study is convenient sampling method.

\section{LIMITATIONS OF STUDY}

- This watch makes a point to the respondents of Chennai since it were Along those lines Condition inferred should in like manner be completely impressive handiest for this alliance.

- The recognition of the test ought to be obliged to crucial information, which are given by the respondents.

\section{SOURCES OF DATA COLLECTION}

\subsection{Primary Data}

Its first hand data taken for study. Data is collected through questionnaire method.

\subsection{Secondary Data}

It is already researched data. It is from magazine, journals, etc.

\section{DATA ANALYSIS AND INTERPRETATION}

Table 1: Recognize Approximately this Website

\begin{tabular}{|c|c|c|c|}
\hline S.NO & PARTICULARS & $\begin{array}{c}\text { NO OF } \\
\text { RESPONDENTS }\end{array}$ & PERCENTAGE \\
\hline 1 & Search Engine & 70 & $70 \%$ \\
\hline 2 & Social Media & 05 & $05 \%$ \\
\hline 3 & Family & 10 & $10 \%$ \\
\hline 4 & Friends & 15 & $15 \%$ \\
\hline & Total & 100 & $100 \%$ \\
\hline
\end{tabular}


An Analytical Study of Search Engine Optimization (SEO) Techniques: To Maximize Number of Travelers on an E-Content Material Website

\section{Inference}

Most of the respondents recognize the website through search engines. 15\% of respondents recognizes the website through friends. $10 \%$ of respondents recognize the website through family and only $05 \%$ of respondents recognize the website through social media.

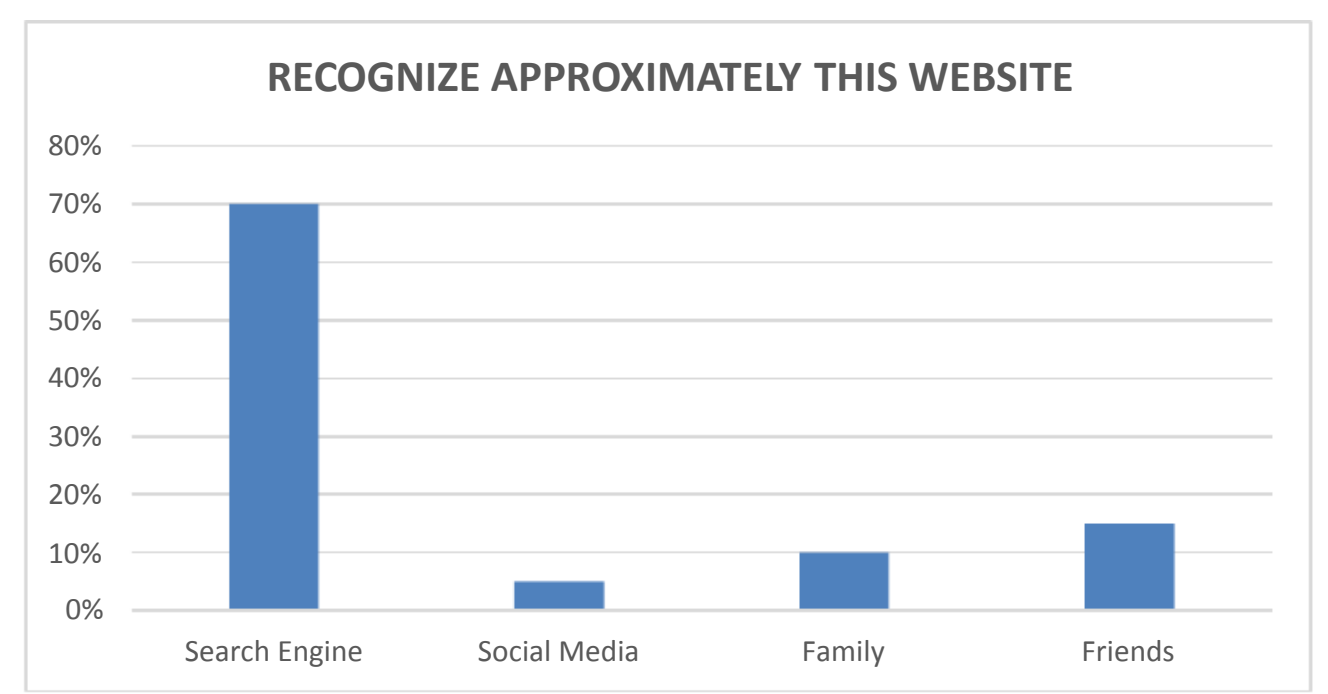

Figure 1

Table 2: Search Engine did you use:

\begin{tabular}{|c|c|c|c|}
\hline S.NO & PARTICULARS & NO OF RESPONDENTS & PERCENTAGE \\
\hline 1 & Google & 80 & $80 \%$ \\
\hline 2 & Yahoo & 10 & $10 \%$ \\
\hline 3 & Linkedin & 5 & $5 \%$ \\
\hline 4 & Rediff & 5 & $5 \%$ \\
\hline & Total & 100 & $100 \%$ \\
\hline
\end{tabular}

\section{Inference}

Most of the respondents recognize the website through search engines. $15 \%$ of respondents recognizes the website through friends. $10 \%$ of respondents recognize the website through family and only $05 \%$ of respondents recognize the website through social media.

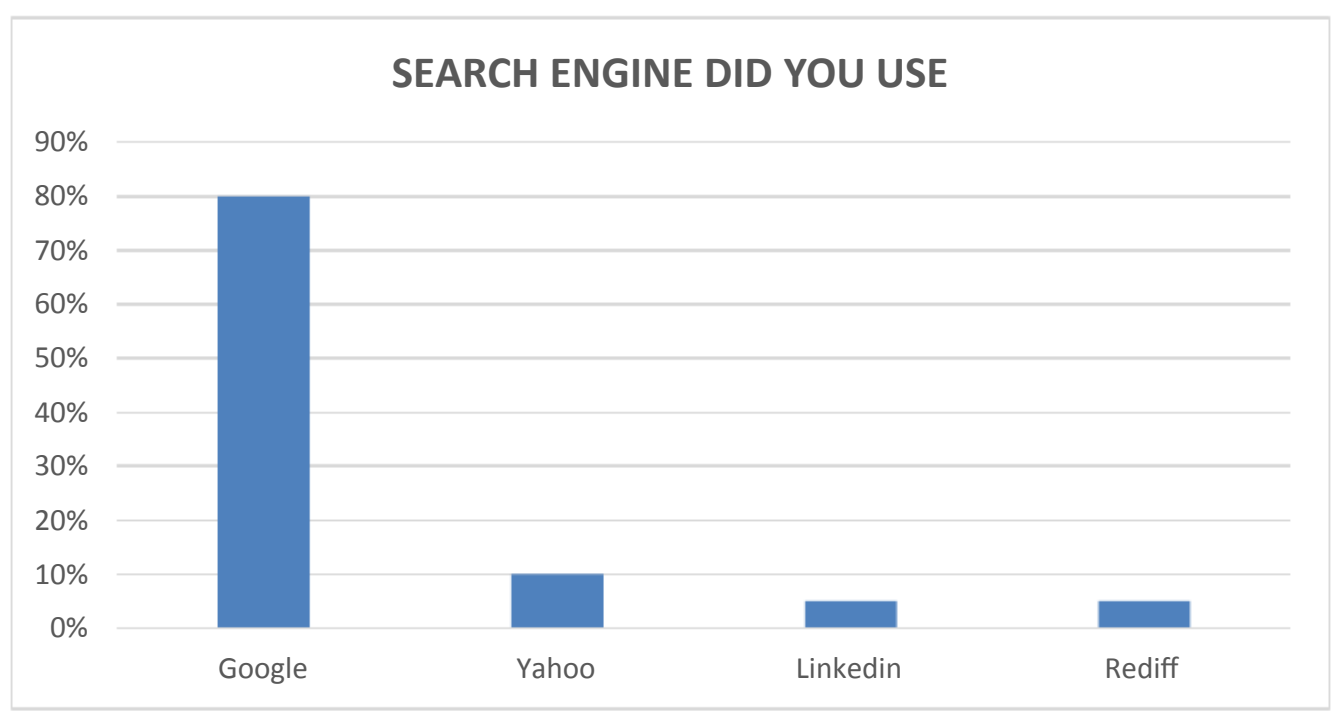

Figure 2 


\section{CHI - SQUARE TEST}

Table 1: Recognises Approximately this Website:

\begin{tabular}{|c|c|c|c|c|}
\hline $\mathbf{O}$ & $\mathbf{E}$ & $(\mathbf{O}-\mathbf{E})$ & $(\mathbf{O}-\mathbf{E})^{\mathbf{2}}$ & $(\mathbf{O}-\mathbf{E})^{\mathbf{2}} / \mathbf{E}$ \\
\hline 70 & 60 & 10 & 100 & 1.666 \\
\hline 05 & 60 & -55 & 3025 & 50.416 \\
\hline 10 & 20 & -10 & 100 & 05 \\
\hline 15 & 05 & 10 & 100 & 20 \\
\hline
\end{tabular}

\section{Null Hypothesis}

There is no significant difference website

\section{Alternative Hypothesis}

There is significant difference between website

Chi Square Test $=(\mathrm{O}-\mathrm{E}) 2 / \mathrm{E}$

Chi Square Test $=77.08$

Degrees of Freedom

$\mathrm{V}=[\mathrm{r}-1][\mathrm{c}-1]$

$\mathrm{V}=[2-1][2-1]$

$\mathrm{V}=1 \mathrm{X} 1$

$\mathrm{V}=1$

Table Value $[$ T.V] $=3.84$

Calculated Value $[\mathrm{C} . \mathrm{V}]=77.08$

Therefore, Calculated Value (C.V) $>$ Table Value (T.V)

\section{FINDINGS AND SUGGESTION}

- Most of the respondents recognize the website through search engines.

- Most of the respondents recognize the website through search engines.

\section{CONCLUSION}

We can land up from the investigation that product Optimization is starting at now one among the essential fundamental factors in pace of a site's thriving and commonness. There are various contraptions and methodologies on the off chance that you need to be actualized so on improve your website at the standard web files. At this moment, strategies have been done particularly, content advancing and web fundamentally based presence promoting, to enhance the scope of visitors/Traffic on the area. From the examination, it okay can likewise be surmised that Traffic through Organic Searches is over $60 \%$ and consequently melding programming Optimization in the Business Model is of most serious significance to each unmarried Online Business.

\section{REFERENCES}

[1] Bih-Yaw Shih, Chen-Yuan Chen and Zih-Siang Chen, "An Empirical Study of an Internet Marketing Strategy for Search Engine Optimization," Human Factors and Ergonomics in Manufacturing \& Service Industries, Wiley Periodicals, Vol. 23, Issue 6, November/December, 2013, pp. 528-540. 
An Analytical Study of Search Engine Optimization (SEO) Techniques: To Maximize Number of Travelers on an E-Content Material Website

[2] Khalil ur Rehman and Muhammad Naeem Ahmed Khan, "The Foremost Guidelines for Achieving Higher Ranking in Search Results through Search Engine Optimization," International Journal of Advanced Science and Technology Vol. 52, March, 2013.

[3] Dimitrios Giomelakis and Andreas Veglis, "Employing Search Engine Optimization Techniques in Online News Articles," Studies in Media and Communication Vol. 3, No. 1, June 2015.

[4] Y. Vijay Bhaskar Reddy, S. Nagarjuna Reddy and Dr S. Sai Satya Narayana Reddy, Efficient Web-Information Retrieval systems and Web Search Engines: A Survey, International Journal of Mechanical Engineering and Technology 8(12), 2017, pp. 594599.

[5] M. Sathya, S. Madhan, U. Jothilakshmi, VWDRE - A Vision-Based Approach for Mining Data from Search Engine Result Pages. International Journal of Civil Engineering and Technology,8(9), 2017, pp. 973-982

[6] Raman Deep Gautam and Dr. Sanjay Kumar Bahl, Impact of Social Media on Students in Private/Professional Higher Education - A Study of Punjab, Journal of Management,5(4), 2018, pp. 112-124

[7] Abdul Rahim Ahmed Munshi, Impact of Social Media Reviews on Cine Enthusiasts with Special Reference to Bollywood Movies, International Journal of Management, 10 (2), 2019, pp. 177-186

[8] Rahim Munshi, Influence of Social Media Marketing on the Admission Decisions in Higher Education in the City of Vadodara. Journal of Management, 5(4), 2018, pp. 407414

[9] Dr. Suryakant B Patil, Ashlesha Sawant and Dr. Preeti Patil, Improvement in the Efficiency of Web Based Search Engines By Increasing Page Rank Based on Referring Factors, International Journal of Information Technology \& Management Information System (IJITMIS), 5(1), 2014, 53-59 